\title{
Speech Acts and Rationality
}

\author{
Philip R. Coben \\ Artificial Intelligence Center \\ SRI Internationa! \\ and \\ Center for the Study of Language and Information \\ Stanford University
}

\author{
Hector J. Levesque \\ Department of Computer Science \\ University of Toronto*
}

\section{Abstract}

This paper derives the basis of a theory of communication from a formial theory of rational interaction. The major result is a demonstration that illorutionary acts need not be primitive, and need not be recognised. is a test rase, we derive Searle's conditions on requesting from principles of rationality coupled with a Ciricean theory of imperatives. The theory is shown to distinguish insincere or nonserious imperatives from true requests. Fixtensions to indirect speech arts, and ramifications for natural language systems are also briefly diseussed.

\section{Introduction}

The unifying theme of much current pragmatics and discourse research is that the coherence of dialogne is 10 be found in the interaction of the conversants plans. That is, a speaker is re. garderl as planning his itteranres in achic've his goals. which may involve infuenring a herarer by the use of communicative or "speech acts. On recrivitin an utterance realizing such an action. the hearer altempts 10 infer the spenker's goal(s) and to understand how the utterance furthers them. The heares then arlopts new goals (1. a.. 10 re-pond to a request, to clarify the previnus speaker's utterance or unal) and plans his own utlepances to arhie've those. A ronversation ensues. '

This view of language as purposeful arrion has pervaded computational linguisties researets, and has resulted in numerous protorype syserms $[1,2,3, \therefore, 9.25,27]$. However, the formal foundarions underlying thene systems have been unspecified or indenperified. In this tate of affairs. one cannot chararterize what a wintem shoudt des independently from what it does.

This paper begins to rectify this situation by presenting a formalization of rationa! interaction. upon which is erected the

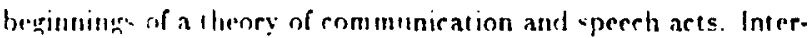
action is revived from principles of rational action for individual agents, as well as principles of belief and goal adoption among agents. The bassis of a theory of purposefil communication thus

- Feilow of the Canadian Iristitiute for A':vanefd Regearch.

'This research was madiv pressilite in part hy a gift from the Systems Devel. opment foundation. and in part by surpere forn the Defense Advaneed

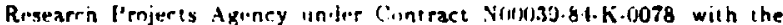
Vaval filectronic Systems C'smmand. The views and ennelusions enn. tained in this dorument are those of the authors and should not be inter. ureted is representative of thonfficial policies, fither expressed or implied. of the Defense Advanced Respareh Projects Agrncy or the United Staces Government. Much of this researrh was done when the second author was employed at the Fairehild Ciamera and Instrument Corp. emerges as a consequence of principles of action.

\subsection{Speech Act Theory}

Speech act theory was originally ronceived as part of action theory. Many of Austin's [1] insights about the nature of peech acts, felirity conditions, and modes of failure apply equally well to non-communicative actions. Searle [26] repeatedly mentions that many of the conditions he attributes to various illocutionary arts (such as requests and questions) apply more generally to non-communicative action. However, researchers have graclually lost sight of their roots. In recent work $[28]$ illorutionary acts are formalized, and a logic is proposed. in which propertien of It's (e.g. "preparatory conditions" and "modes of arhievement ${ }^{\top}$ ) are primitively stipulated. rather than derived from more basic principles of action. We believe this approach missess significant generalities. Thus paper shows how to derive properties of illocutionary acts from principles of racionality, updating the formalism of $\{10\}$.

Work in Artificial Intelligence provided the first formal grounding of speech act theory in terms of planning and plan

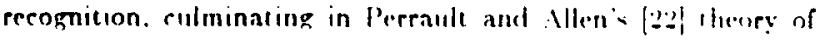
indirect speech ares. Mueh of our researeh is imspired by their analyses. Howeser, one major ingredient of their theory rau be shown to be redundant $[10)$ illocutionary acts. Mll the inferential power of the reregnition of their lllocutionary arts was alrendy available in other operators". Vevertheless. the natu. al langlage syseems hased on this approach $[1$, if always had to recognize which illocutionary act was performed in order 10 respond to a user's utterance. Since the illocutionary arts were unnecessary for achieving their effects, so 100 was their reengnition.

The stance that illocutionary acts are not primitive, and need not be reengnizedi. is a lib.rating one. (Jnce taken, it beromess apparent that many of the difficulties in applying iperech art theory to discourse, or to computer systems, stem from taking these acts too seriously - i.e., too primitively.

\section{Form of the argument}

We show that illocutionary acts need not be primitive by deriving Searle's conditions on requesting from an independentlymotivaled theory of action. The realm of communicative action is entered following Grice $[13\}$ - by postulating a correlation between the itterance of a sentence with a certain syntactic feature (e.g., its dominant clause is an imperative) and a complex 
propositional attitude expressing the speaker's goal. This attitude becomes true as a result of uttering a sentence with that feacure. Because of certain general principles governing beliefs and goals, other causal consequences of the speaker's having the expressed goal can be derived. Such derivations will be "summarized" as lemmas of the form "If (conditions) are true, then any action making (antecedent) true also makes (consequent) true." These lemmas will be used to characterize illocutionary acts, though they are not themselves acts. For example, the lemma called REQUEST will characterize a derivation that shows how a bearer's knowing that the speaker has certain goals can cause the hearer to act. The conditions licensing that chain will be collected in the REQUEST lemma. and will be shown to subsume those stipulated by Searle $[26]$ as felicity conditions. However, they have been derived here from first principles, and without the need for a primitive action of requesting.

The benefits of this approach become clearer as other illocutionary acts are derived. We have derived a characterization of the speech act of informing. and have used it in deriving the sperech act of questioning. The latter derivation also allows us to distingnish real questions from teacher/student questions. and rhetorical questions. However, for hrevity, the discussion of these speech acts has been omitted.

Indirect speech acts can be handled within the framework. although. again. we cannot present the analyses here. Briefly. axioms similar to those of Perrault and Nlen \{22| ran be supplied enabling one to reason that an agent has a goal that $\eta$. given that he also has a goal $p$. When the $p$ s and $q$ 's are themselves goals of the hearer (i.e.. the speaker is trying to get the hearer $t o$ do something), then we can derive a set of lemmas for indirect requests. Many of these indireet request lemmas correspond to what have been called "short-cireuited" implicatures, which. it was suggested [21] underlie the processing of utterances of the form "Can you do X?". "Do you know y?". ete. Lemma formation and lemma application thus provide a familiar model of hort-rircuiting. Furthermore, this approach shows how one ran use general purpose reasoning in concert with ennventionalized forms (e.g., how one can reason that $r$ an you reach the $s a l t^{*}$ is a request to pass the salt). a problem that has plagued most theories of speech acts.

The plan for the paper is to construct a formalism based on a theory of action that is sufficient for rharacterizing a request. Most of the work is in the theory of action, as it should be.

\section{The Formalism}

To achieve these goals we need a carefi:lly worked out (though perhaps incompiete) theory of ratinnal action and interaction. T'le thenry will be expressed in a Ingic whose mndel theory is bused (loosely) on a possible-worlds semantics. We shall propose a logic with four primary modal nperators -.- BELief, BMB, GOAL. and AFTER. IVith these, we shall characterize what agents need to know to perform actions that are intended to achieve their goals. The igents do so with the knowledge that other agrents operate similarly. Thuss. agents have beliefs about ather's ycals, and they have goals to infuence others' beliefs and grals. The interration of these operators follows that of Moore $[20\}$, who aralyies how an agent's knuwledge affects and is afferted by his actions. by meshing a possible-worlds model of knowledge with a situation calculus mudel of action [18]. By adding GOAL, we can begin to talk about an arent's plans, which can include his plans to influence the beliefs and goals of others.

Intuitively, a model for these operators includes courses of events (i.e., sequences of primitive acts) 2 that characterize what has happened. Courses of events (c.o.e.'s) are paths through a tree of possible future primitive acts, and after any primitive act has occurred, one can recover the course of events that led up to it. C.o.e.'s can also be related to one another via accessiblity relations that partake in the semantics of BEL and GOAL. Further details of this semantics must await our fortheoming paper [17].

As a general strategy, the formalism will be too strong. First, we have the usual consequential closure problems that plague possible-worlds modets for belief. These, however. will be accepted for the time being. Second, the formalism will describe agents as satisfying certain properties that might generally be true, but for which there might be exceptions. Perhaps a process of non-monotonic reasoning could smooth over the exceptions, but we will not attempt to specify such reasoning here. Instead, we assemble a set of basic principles and examine their consequences for speech act use. Third, we are willing to live with the difficulties of the situation calculus model of action - e.g., the lack of a way to capture trie paraltelism. and the frame problem. Finally, the formalism should be regarded as a description or specification of an agent, rather than one that any agent could or should use.

Our approach will be to ground a theory of communiration in a theory of rational interaction, itself supported by a theory of rational action. which is finally grounded in mental states. Accortingly, we first need to describe the behavior of BEL. BMB. GOAL and AFTER. Then. these operators will be combined to describe how agents' goals and plans influence their actions. Then, we characterize how having beliefs about the beliefs and goals of others can affect one's own beliefs and goals. Finally, we characterize a request.

To be more sperific, here are the primitives that will be used, with a minimal explanation.

\subsection{Primitives}

Assume $p, q, \ldots$ are schema variables ranging over wfis, and $\mathrm{a}, \mathrm{b}$. . are schematic variailes ranging over acts. Then the following are wifs.

\subsubsection{Wifs}

$$
\sim p
$$$$
(p \vee q)
$$

(AFTER a $p$ ! - $p$ is true in all courses of events that obtain from act $a$ 's bappening:. (if a denoces a halting act).

(DONE a). The event denoted by a has just happaned.

(AGT a $x$ ) Agent $x$ is the only agent of act a

$a \leq b$ - Art a presectes act $b$ in the current course of events.

$\exists \equiv p$ where $p$ contains a tree occurrence of variable $z$.

$x=y$

True, False:

(BEL $\times$ p) - p follows from $x$ 's beliefs.

(FOAL $x$ p) - $p$ follows from $x$ 's goals.

(BMB $x$ y p) p p fullows from x's beliels about what is mutually believed by $x$ and $y$.

\footnotetext{
2For this paper, the only events that will be considered are primitive acts. ${ }^{3}$ That is, $p$ is true in all e.oe.'s resulting from concatenating the current c.j.e. with the c.o.e. denoted by $a$.
} 


\subsubsection{Action Formation}

If $a, b, c, d$ range over sequences of primitive acts, and $p$ is a $w$ fif. then the following are complex act descriptions:

a:b - sequential action

a | $\mathbf{b}$ - non-deterministic choice (a or b) action

p? - action of positively testing $p$.

(IF $p$ a b) - conditional action $\stackrel{\text { def }}{=}(\mathbf{p}$ ?:a) $\mid(\sim p$ ?;b), as in dynamic logic.

(UNTIL p a) - iterative action $\stackrel{\text { def }}{=}(\sim p ; a)^{\bullet ; \sim p ? ~(a g a i n, ~ a s ~ i n ~}$ dynamic logic).

The meta-symbol ' $F$ ' will prefix formulas that are theorems, i.e.. that are derivable. Properties of the formal system that will be assumed to hold will be termed Propositions. Propositions will be both formulas that should always be valid, for our forthcoming semantics, and rules of inference that should be sound. io attempt to prove or validate these propositions here, but we do so in $[1]]$.

\subsection{Properties of Acts}

Wie adopt the isulal axioms characterizing how complex actions behave under AFTER, as treated in a dynamic logic (e.g., \{20\}) namely.

Proposition 1 Properties of complez acts ...

(AFTER a:b p) $\equiv$ (AFTER a (AFTER b p)). (AFTER a b p) $\equiv(A F T E R$ a p) $\wedge$ (AFTER b p). (AFTER p? q) $\equiv \mathrm{p} \wedge$ q.

AFTER and DONE will have the following additional proper. ties:

Proposition $2 \forall$ act (AFTER act (DONE $x$ act))

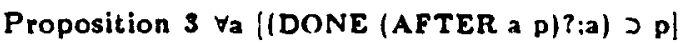

Proposition 4 If $\vdash$ a $S$ then

I $\forall a \quad$ (DONE $x$ ?:a) $\supset$ (DONE, ?;a)

Proposition $5 \mathrm{p} \equiv$ (DONE p?)

Proposition 6 (DONE [(p つ $) \wedge p \mid$ ?) ว (DONE q?)

Our treatment of acts requires that we deal somehow with the 'frame problem" [18]. That is. we must characterize not only what changes as a result of doing an action, but also what does not rhange. To approach this problem, the following notation will be convenient:

Definition 1 (PRESERves a p) $\stackrel{\text { fep }}{=}$ p $\supset$ (AFTER a p)

Of course, all theorems are preserved.

Temporal concepts are introduced witl. DONE (for past happenings) and $\diamond$ (read "eventually"). To say that $p$ was true at sorme point in the past. we use Ja (DONE p?:a). $\diamond$ is to be regarded in the "branching time' sense $[11]$, and will be defined more rigorously in $[17\rceil$. Essentially. $\diamond p$ is true iff for all infinite extensions of any course of events there is a finite prefix satisfying $p$. $O p$ and $O \sim p$ are jointly satisfiable. Since $O_{p}$ starts "now", the following property is aiso true,

'(AFTER $t$ (DONE $t$ )), where $t$ is term denoting a primitive act (or a sequence of primitive acts), is ant always true since an act nay change the values of terms (e.g.. an election changes the value of the term (PRESIDENT U.S.))
Proposition $7+p \supset$ op

Also, we have the following rule of inference:

Proposition $8 / f \vdash \alpha \supset \beta$ then $\diamond(\alpha \vee p) \supset \diamond(\not \vee p)$

\subsection{The Attitudes}

Neither BEL, BMB, nor GOAL characterize what an agent. actively believes, mutually believes (with someone else), or has as a goal, but rather what is implicit in his beliefs. mutual beliefs, and goals. 's That is, these operators characterize what the world would be like if the agent's beliefs and mutual beliefs were true, and if his goals were made true. Importantly, we do not include an operator for wanting, since desires need not be consistent. We assume that once an agent has sorted out his possibly inconsistent desires in deciding what he wishes to arhieve, the worlds he will be striving for are consistent. ('onversely, reengnition of an agent's plans need not consider that agent's possibly inconsistent desires. Furthermore, there is also no explicit operator for intending. If an agent intends 10 bring about $p$, the agent is usually regarded as also being able to bring about p. By using GOAL, we will be able to reason about the end state the agent is aiming at separately from our reasoning about his ability to achieve that state.

For simplicity, we assume the usual Hintikka axiom srhemata for BEL $|15|$, and we introduce KNOW by definition:

Definition 2 (KNOW $\times p) \stackrel{\text { def }}{=} p \wedge(B E L \times p)$

\subsubsection{Mutual Belief}

Human communication depends crucially on what is mutually believed $\{1,6,7,0,22,23,24\}$. We do not use the standard definitions, but employ (BMB y $\times$ p), which stands for $y$ 's belief that it is mutually believed between $y$ and $x$ that $p$. (BMB $y$ $x p)$ is tnie iff (BEL y $(p \wedge$ (BMB $x$ y p) $)$ ). BMB has the following properties:

Proposition 9 (BMB y $\times$ p^q) $\equiv(B M B$ y $\times p) \wedge$

(BMB y $x$ q)

Proposition 10 (BMB y $\times$ p $\supset q) \supset$

$((B M B$ y $\times p) \supset(B M B$ y $\times q))$

Proposition $11 / / \vdash \alpha$ I I then

$r(B M B$ y $x x) \supset($ BMB y $x$ y)

Also, we characterize mutual knowledge as:

Definition $3(M K \times y$ p) $\stackrel{\text { def }}{=} p \wedge(B M B \times y p) \wedge$ (BMB y $\times$ p) $)^{7}$

${ }^{5}$ For an expluration of the issues involved in explicit vs. implicit belief, see [16].

'Notice that (BMB $y \times p) \not(B M B \times y p)$.

'This definition is not entirely correct, but is adequate for present purposes. 


\subsubsection{Goals}

For GOAL, we have the following properties:

Proposition 12 (GOAL $\times$ (GOAL $\times$ p)) つ (GOAL $\times$ p)

If an agent thinks he has a goal, then he does.

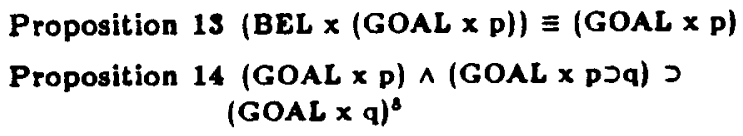

The following two derived rules are also useful:

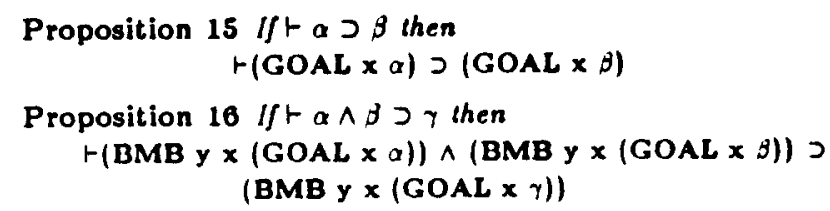

More properties of GOAL follow.

\subsection{Attitudes and Rational Action}

Next, we must characterize how beliefs. goals. and actions are related. The interaction of BEL and AFTER will be pattemed after . Moore's analysis [20]. In particular, we have:

Proposition $17 \forall x$, act (AGT a $x$ ) $>$

(AFTER act (KNOW $\times$ (DONE act)))

Igents know what they have done. Moreover, they think certain - ffects of their own actions are achieved:

\section{Proposition 18 (BEL $\times$ (RESULT $\times$ a $p)$ ) \\ (RESULT $\times$ a (BEL $\times$ p)). where \\ Definition 4 (RESULT $\times$ a p) $\stackrel{\text { def }}{=}$ (AFTER a p) $\wedge$ (AGT a $x$ )}

The major addition we have made is GOAL. which interacts tightly with the other operators.

IVe will say a rational agent only adopts goals that are achievable. and accepts as "desirable" those states of the worid that are inevirable. To characterize inevitabilities, we have

Definition 5 (ALWAYS p) $\stackrel{\text { del }}{=} \forall a$ (AFTER a p)

This says that no matter what happens, $p$ is true. Clearly, we want

Proposition $19 \mathrm{If} / \mathrm{n}$ then + (BEL $\times$ (ALWAYS $\alpha$ ))

That is, theorems are believed to be alwoys true.

inother property we want is that no sequence of primitive acts is forever ruled out from happening.

Proposition $20 \vdash \forall a($ ACT a) $\supset \sim($ ALWAYS $\sim$ (DONE a)), wiure (ACT a) $\stackrel{\text { gef }}{=} \sim$ (AFTER a -(DONE a))

One important variant of ALWAYS is (ALWAYS $x$ p) (relative to an agenr), which indicates that no matter what that agent does, $p$ is true. The definition of this version is:

\section{Definition $B$ (ALWAYS $x$ p) $\stackrel{\text { def }}{=} \forall a$ (RESULT $\times$ a p)}

A useful instance of ALWAYS is (ALWAYS $p \supset q$ ) in which no matter what happens, p still implies q. We can now distinguish between $p \supset q$ s being logically valid, its being true in all courses of events, and its merely being true after some event happens.

- Notice that if $p \supset q$ is true (or even believed) but (GOAL $\times p \supset q$ ) is not true, we should not reach this conclusion since some act could make it taise.

\subsubsection{Goals and Inevitabilities}

What an agent believes to be inevitable is a goal (he accepts what be cannot change).

\section{Proposition 21 (BEL $\times$ (ALWAYS p)) つ (GOAL $\times$ p)}

and conversely (almost), agents do not adopt goals that they believe to be impossible to achieve -

Proposition 22 No futility - (GOAL $\times$ p) $\supset$ $\sim($ BEL $\times$ (ALWAYS $\sim p)$ )

This gives the following useful lemma:

Lemma 1 Inevitable Consequences

(GOAL $\times p) \wedge($ (BEL $\times$ (ALWAYS $p \supset q \| \supset($ GOAL $\times q)$

Proof: By Proposition 21, if an agent believes $p \supset q$ is always true, he has it as a goal. Hence by Proposition $14, q$ follows from his goals.

This lemma states that if one's goal is a c.o.e. in which pholds, and if one thinks that no matter what happens, pدq, then one's goal is a c.o.e. in which $q$ holds. Two aspects of this property are crucially important to its plausibility. First, one must keep in mind the "follows from" interpretation of our propositional attitudes. Second. the key aspect of the connection between $p$ and $q$ is that no one can achieve $p$ without achieving $q$. If someone could do so, then $q$ need not be true in a c.o.t. that satisfies the agent's goals.

Now, we have the following as a lemma that will be used in the speech act derivations:

\section{Lemma 2 Shared Recognition}

$(B M B$ y $\times(G O A L \times P)) \wedge$

(BMB Y $\times$ (BEL $\times$ (ALWAYS p

(BMB $y \times($ GOAL $\times$ q))

The proof is a straightforward application of Lemma 1 and Propositions 9 and 10.

\subsubsection{Persistent goals}

In this formalism. we are attempting to capture a number of properties of what might be called "intention" without postulating a primitive conrept for "intend". Instead, we will combine acts, beliefs. goals, and a notion of commitment built out of more primitive notions.

To :apture une grade of commitment than an agent might have towards his goals, we define a persistent goal. P-GOAL. to be une that the agent will not give up until he thinks it has been saiisfied, or until he thinks he cannot achieve it.

Now, in order 10 state constraints on c.o.e.'s we define:

Definition 7 (PREREQ $\times p$ q) $\stackrel{\text { def }}{=}$

$\forall c($ RESULT $x=q) \supset \exists a(a \leq c) \wedge$ (RESULT $x a p)$

This definition states that $p$ is a prerequisite for $x$ 's achieving $q$ if all ways for $x$ to bring about $q$ resuit in a course of events in which $p$ has been true. Now, we are ready for persistent goals: 


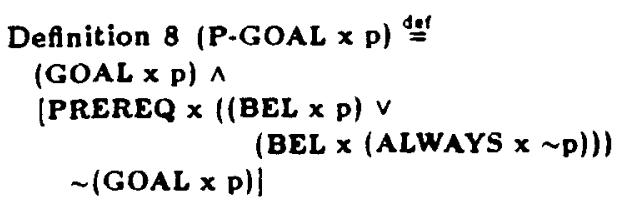

Persistent goals are ones the agent will replan to achieve if his earlier attempts to achieve it fail to do so. Our definition does not say that an agent must give up his goal when he thinks it is satisfied, since goals of maintenance are allowed. All this says is that somewhere along the way to giving up the persistent goal, the agent had to think it was true (or believe it was impossible for him to achieve).

Though an agent may be persistent. he may be foolishly so because he has no competence to achieve his goals. We characterize competence below.

\subsubsection{Competence}

Prople are sometimes experts in certain fields, as well as in their uw il bullily movements. For example. a competent electrician will form correct plans to arhieve world states in which "electrical" tates of affairs obtain. Most adults are competent in achievills world states in which their teeth are brushed, etc. We will say an agent is COMPETENT with respert to $p$ if, whenever he thinks $p$ will true after some action happens, he is correct:

\section{Definition 9 (COMPETENT $\times$ p) $\stackrel{\text { def }}{=}$ $\forall a$ (BEL $\times($ AFTER $\times$ p)) $\supset$ (AFTER a p)}

One property of competence we will want is:

Proposition $23 \forall x$, a (AGT $x$ a) $\supset$ (ALWAYS (COMPETENT $\times$ (DONE $\times$ a))), where

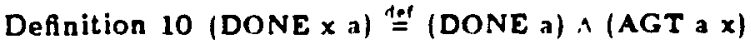

That is. any person is always competent to do the acts of which he is the agent. 'Of course, he is not always competent in arhieve any particular effect.

Finally, given all these properties we are ready to describe rational agents.

\subsection{Rational Agents}

Below are properties of ideally rational agents who adopt persistent geals.

First. agents are careful: they do not knowingly and deliberatcly make their persistent goals impossible for them achieve.

Proposition 24 (DONE $\times$ act) つ (DONE $\times$ p?;act), where $p \stackrel{\text { Aol }}{=}($ P.CBOAL $\times q) \supset \sim$ (BEL $\times$ (AFTER act (ALWAYS $x \sim p)$ )) $v$ $\sim$ (GOAL $\times$ (DONE $\times$ act) $)^{10}$

In other words, no deliberately snooting nnesself in the foot.

Now, agents are cautious in arlopting persistent goais, sinee they must eventually eome to some decision about their leasibility. We require an agent to either come up with a "plan" to

\footnotetext{
${ }^{\circ}$ Because of Proposition 2. all Proposition 23 says is that if a competent agent believes his cwn primitive act halts, it will.

${ }^{10}$ Notice that It is crucial that $p$ be true in the same world in which the agent does act, hence the use "sf "p?:act"
}

achieve them - a belief of some act (or act sequence) that it achieves the persistent goal - or to believe he cannot bring the goal about. That is, agents do not adopt persistent goals they could never give up. The next Proposition will characterize this property of P-GOAL.

But, even with a correct plan and a persistent goal. there is still the possibility that the competent agent never executes the plan in the right circumstances - some other agent has changed the circumstances, thereby making the plan incorrect. If the agent is competent, then if he formulates another plan. it will be correct for the new circumstances. But again, the world could change out from under him. Now, just as with operating systems, we want to say that the world is "fair" - the agent will eventually get a chance to execute his plans. This property is also characterized in the following Proposition:

Proposition 25 Faur Execution - The agent uill prentsally form a plan and exerule "l, believing it arhicves his persistent goal in rircumstances he believes to be appropriate for its surress.

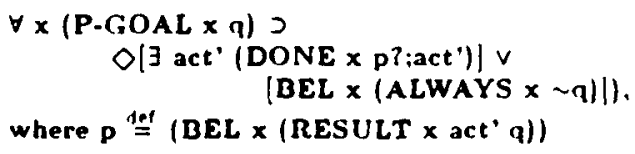

We now give a crucial theorem:

Theorem 1 Consequences of a persistent goal - If someone has a persistent goal of bringing about $p$, and bringing about $p$ is within his area of competence, then eventually either $p$ beromes true or he will believe there is nothing that can be done to achieve p

$$
\begin{gathered}
\forall y(\text { P.GOAL y p) } \wedge \text { (ALWAYS (COMPETENT y p)) } \\
O(p \vee(B E L \text { y (ALWAYS y p })))
\end{gathered}
$$

\section{Proof sketch:}

Since the agent has a persistent goal. he eventually will either find and execute a plan, or will believe there is nothing he can do to achieve the goal. Since he is competent with respect to $p$, the plans he forms will be correct. Since his plan act' is correct, and since any other plans he forms for bringing about $p$ are also correct, and since the world is "fair", eventually either the agent executes his correct plan, making $p$ true, or the agent comes to believe he cannot achieve $p$. A more rigorous proof can be found in the Appendix.

This theorem is a major cornerstone of the formalism. telling us when we can conclude $O p$. given a plan and a goal. and is used throughout the speech act analyses. If an agent who is not COMPETENT with respect to $p$ adopts $p$ as a persistent goal, we cannot conclude that eventually either $p$ will be tne (or the agent will think he cannot bring it about), since the agent could forever create incorrect plans. If the goal is not persistent, we also cannot conclude $O p$ since the agent could give it up without achieving it.

The use of $\diamond$ opens the formalism to MeDermott's "Little Nell" paradox [19]. "I In our context, the problem arises as follows: First, since an agent has a persistent goal to achieve $p$,

\footnotetext{
"Little Nell is tied to the railroad tracks, and will be mashed by the next train. Dudley Doright is planning to save her. MeDermott claims that. aceording to variuus Al theories of planning, he never will, even though he al waya knows just what to do.
} 
and we assume here he is always competent with respect to $p$, $O_{p}$ is true. But, when $p$ is of the form $\circlearrowleft_{q}$ (e.g., $O$ (SAVED LITTLE-NELL)), $\diamond \diamond_{q}$ is true, so $\diamond q$ is true as well. Let us assume the agent knows all this. Hence, by the definition of P.GOAL, one might expect the agent to give up his persistent goal that $\diamond q$, since it is already satisfied!

On the other hand, it would appear that Proposition 25 is sufficient to prevent the agent from giving up his goal too soon, since it states that the agent with a persistent goal must act on it, and, moreover, the definition of P.GOAL does not require the agent to give up his goal immediately. For persistent goals to achieve $\diamond q$. within someone's scope of competence, one might think the agent need "only" maintain $\diamond_{q}$ as a goal, and then the other properties of rationality force the agent to perform a primitive act.

Unfortunately, the properties given so far do not yet rule out Litule Nell's being mashed, and for two reasons. First, NIL denotes a primitive act - the empty sequence. Hence, doing it would satisfy Proposition 25 , but the agent never does anything substantive. Second, doing anything that does not affect $q$ also satisfies Proposition 25, since after doing the unrelated act, Oq is still true. We need to say that the agent eventually acts on q? To do so, we have the following property:

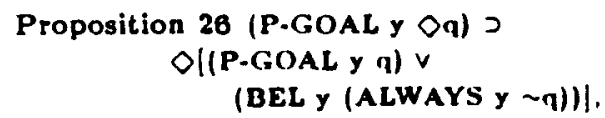

That is. eventually the agent will have the persistent goal that q, and hy P'roposition 25. will act on it. If he eventually comes to believe he cannot bring about $\mathrm{q}$, he eventually comes to believe he canuot bring about eventually $q$ as well, allowing him to give up his persistent goal that eventually $\mathbf{q}$.

\subsection{Rational Interaction}

This ends our discussion of single agents. We now need to chararterize rational interaction sufficimuly to handle a simple requ'st. First, we discuss cooperative agents, and then the effects of uttering sentences.

\subsubsection{Properties of Cooperative Agents}

We describe agents as sincere, helpful, and more knowledgeable than others about the totth of sone state of affairs. Essentially. these roncepts capt ure (quite cimplistic) constraints on influerc. ine somenne clse's beliefs and goals. and on adopting the beliefs and goals of somenne eise as one's own. Wore refined versions are certainly desirable. (ittimately. we expect such properties of conperative agents, as emberded in a theory of rational interaction. in provide a formal description of the kinds of conversarional behavior Crice $[1+1]$ describes with his conversational maxims".

First, we will say an agent is SINCERE with respect to $p$ if whenever his goal is to get someone else to believe $p$, his goal is in fact to get. that person to know $\mathrm{p}$.

Definition 11 (SINCERE $\times$ p) $\stackrel{\text { ded }}{=}$

(GOAL $\times($ BEL Y p)) $\supset$ (GOAL $\times($ KNOW Y P))
An agent is HELPFUL to another if he adopts as his own persistent goal another agent's goal that he eventually do something (provided that potential goal does not conflict with his own).

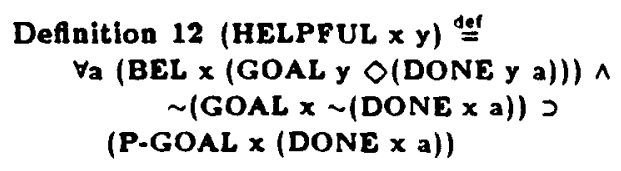

Agent $x$ thinks agent $y$ is more EXPERT about the true of $p$ than $x$ if he always adopts $x$ 's beliefs about $p$ as his own.

$$
\begin{aligned}
& \text { Definition } 13(\text { EXPERT y } \times \text { p) } \stackrel{\text { def }}{=} \\
& (\text { BEL } \times(\text { BEL y P })>(\text { BEL } \times \text { p })
\end{aligned}
$$

\subsubsection{Uttering Sentences with Certain "Features"}

Finally, we need to describe the effects of uttering sentences with certain "features" $\mid 14\}$, such as mood. In particular, we need to characterize the results of uttering imperative, interrogative, and declarative sentences "2 Our descriptions of these effects will be similar to Grices's [13] and to Perrault and Allen's [22] "surface speech acts". Many times, these sentence forms are not used literally to perform the corresponding speech acts (rerquests, questions, and assertions).

The fcllowing is used to characterize uttering an imperacive:

Proposition 27 Imperatives:

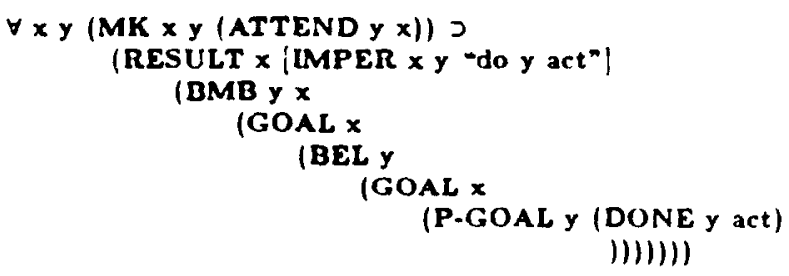

The ac: 'IMPER speaker hearer 'p] stands for "make $p$ imie". Proposition 27 states that if it is mutually known that $y$ is at. tending to $x,{ }^{13}$ then the result of uttering an imperative to $y$ to make it the case that $y$ has done action act is that $y$ thinks it is mutually believed that the speaker's goal is that $y$ should think his goal is for $y$ to form the persistent goal of doing act.

We aisu need in assert that IMPER preserves sincerity about the speakir's rosls and helpfulness. These restrictions could be insened. but maintaining them is simpler.

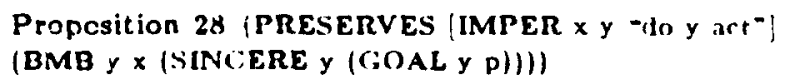

All liricean teature"-based theories of communication need to accurnt for cases in which a speaker uses an utterance with a featurs, but does not have the attitudes (e.g.. beliefs, and goals)

\footnotetext{
${ }_{12}$ Flowever, we can only present the analysis of imperatives here.

${ }^{1}$ If it is not mutually known that $y$ is attending, for example, if the speaker is not speaking to an audience, then we do not say what the result of uttering an imperative is.
} 
usually attributed to someone uttering sentences with that feature. Thus, the attribution of the attitudes needs to be contextdependent. Specifically, proposition 28 needs to be weak enough to present nonserious utterances such as "go jump in the lake" from being automatically interpreted as requests even though the utterance is an imperative. On the other hand, the formula must be strong enough that requests are derivable.

\section{Deriving a Simple Request}

In making a request, the speaker is trying to get the hearer to do an act. We will show how the speaker's uttering an imperative to do the act leads to its eventually being done. What we need to prove is this:

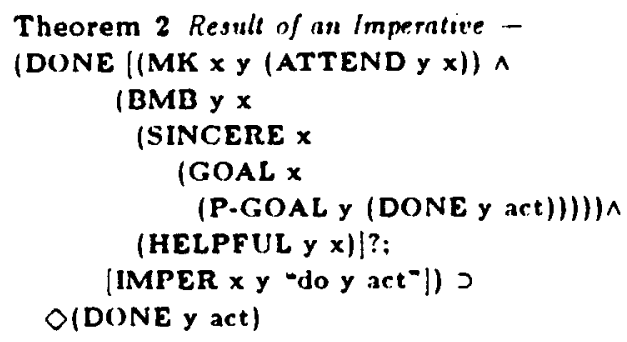

Wie will give the major steps of the proof in Finure 1. and point to their justifications. The full-fiedged proofs are left to the energertic reader. All formulas preeceded by a - are supposed lu be i rue just prior to performing the IMPER, are preserved by it. and thus are implicitly conjoined to formulas 2 - 9. By their placement in the proof, we indicate where they are necessary for making the deductions.

Fisentially, the proof procreds as follows:

If $i t$ is mutually known that $y$ is attending to $x$, and $y$ thinks it is mutually believed that the o-conditions hold, then x's uttering at imperative to y to do some artinn results in formula (2). Since it is mutually believed $x$ is sincere about his gnals, then $(3)$ it is mutually betieved his goal inly is that y form a persistent goal (n) to the act. Since everyone is always competent to do acts of which they are the agent. ( 1 ) it is mutually believed that the art will eventually be done. or $y$ will think it is forever impossible 10 do. But since no halting act is forever impossible to do, it is (j) mutually believed that $x$ 's goal is that $y$ eventuaily do it. Hence, (6) y thinks $x$ 's goal is that $y$ eventually do the art. Yow. since $y$ is helpiully disposed towards $x$, and has no objections 10 roing the act. ( 7 ) y takes it on as a persistent goal. Since he is always competent about doing his own acts, (8) eventually it will be done or he will think it impossible to do. Again. since it is not forever impossible. (I) he will eventually do it.

W. have shown how the performing of an imperative to to an art leacis to the act's eventually being done. We wish to rreate a number of lemmas from this proof (and others like it) to characterize illocutionary arts.

\section{Plans and Summaries}

\subsection{Plans}

A plan for agent " $\mathrm{x}$ " to achieve some goal " $\mathrm{q}$ " is an action term " $\mathrm{a}$ " and two sequences of wifs " $p_{0} ", " p_{1}$ ". ... " $p_{k}$ " and " $q_{0}$ ", " $q_{1}$ " ,.. " $q_{k}$ " where " $q_{k}$ " is " $q^{*}$ and satisfying
1. $\vdash\left(\operatorname{BEL} \times\left(p_{0} \wedge p_{1} \wedge \ldots \wedge p_{k}\right) \supset\right.$ (RESULT $x$ a $\left.q_{0} \wedge p_{1} \wedge \ldots \wedge p_{k}\right)$ )

2. $\vdash\left(\right.$ BEL $\times\left(\right.$ ALWAYS $\left.\left.\left.\left(p_{i} \wedge q_{1-1}\right) \supset q_{1}\right)\right)\right) i=1,2 \ldots k$

In other words, given a state where " $\mathrm{x}$ " believes the " $p_{i}$ ", he will believe that if he does " $\mathrm{a}$ " then " $q_{0}$ " will hold and moreover. given that the act preserves $p_{i}$, and he believes his making " $q_{i-1}$ " true in the presence of $p_{i}$ will also make " $q_{i}{ }^{n}$ true. Consequently, a plan is a special kind of proof that

$\vdash\left(B E L \times\left(\left(p_{0} \wedge \ldots \wedge p_{k}\right) \supset(\right.\right.$ RESULT $x$ a $\left.\left.q)\right)\right)$

and therefore, since

$(B E L \times p) \supset(B E L \times(B E L \times p))$

and

$(B E L \times(p \supset q)) \supset((B E L \times p) \supset(B E L \times q))$, are axioms of belief, a plan is a proof that

$\vdash\left(\operatorname{BEL} \times\left(p_{0} \wedge \ldots \wedge p_{k}\right)\right) \supset($ BEL $\times(\operatorname{RESULT} \times$ a $(1))$

Among the corollaries to a plan are

$\vdash\left(\operatorname{BEL} \times\left(\left(p_{0} \wedge \ldots \wedge p_{1}\right) \supset\left(\operatorname{RESULT} \times\right.\right.\right.$ a $\left.\left.\left.\eta_{1}\right)\right)\right) i=l_{1} \ldots k$

and

$\vdash\left(\right.$ BEL $\times\left(\left(p_{i} \wedge \ldots \wedge p_{j}\right) \supset\left(\right.\right.$ ALWAYS $\left.\left.\left.q_{i-1} \supset q_{j}\right)\right)\right)$ $i=1 . \ldots k j=i \ldots k$

There are two main points to be made about these corollaries. First of all, since they are theorems. the implications can be taken to be believed by the agent ${ }^{-*}$ in every state. In this sense, these wffs express general methods believed to achieve certain effects provided the assumptions are satisfied. The second point is that these corollaries are in precisely the form that is required in a plan and therefore can be used as justification for a step in a future plan in much the same way a lemma becomes a single step in the proof of a theorem.

\subsection{Summaries}

We therefore propose a notation for describing many stepe of a plan as a single summarizing operator. A summary consists of a name, a list of free variables, a distinguished free variable called the agent of the summary (who will always be list id first), an E.fert which is a wfr, a optional Body which is either an action or a wff and finally, an optional Gate which is a wff. The understanding here is that summaries are associated with agent and for an agent " $x$ " to have summary " $u$ ", then there are three cases depending on the body of "u":

1. If the Body of " $u$ " is a wff, then

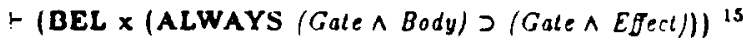

2. If the Body of " $u$ " is an action term, then

$\vdash$ (BEL $\times$ (Gate $\supset$ (RESULT agent Body (Gate ^ Effect)) ) )

${ }^{18}$ Of course, many actions change the truth of their preconditions. Handling such actions and preconditions is straightforward. 


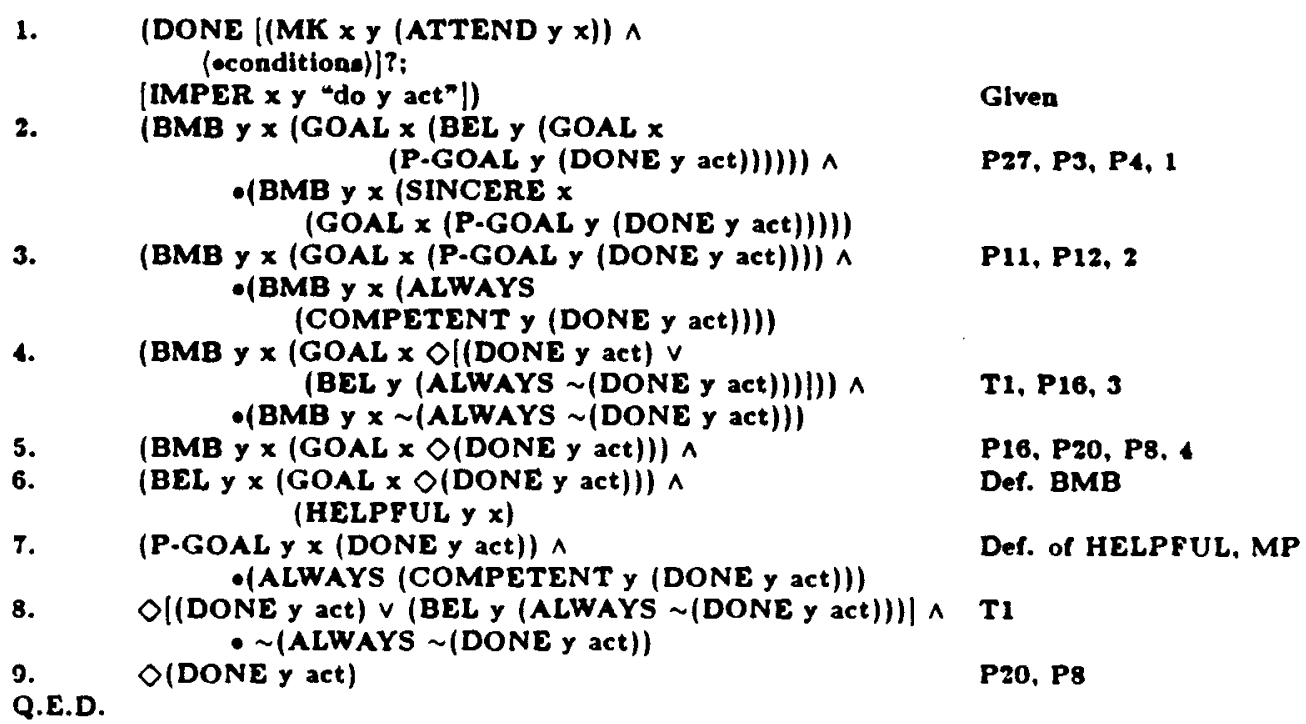

Figure 1: Proof of Theorem $2-$ An imperative to do an act results in its eventually being done. ${ }^{14}$

One thing worth noting about summaries is that normally the * fis used above

$\vdash$ (BEL $\times($ Gaie 2 ...) $)$

will follow from the more general wf

$\vdash$ Gale $\supset$...

However. this need not be the case and different agents could have different summaries (even with the same name). Saying that an agent has a summary is no more than a convenient way of saying that the agent always believes an implication of a certain kind.

\section{Summarization of a Request}

The following is a summary named REQUEST that captures steps 2 through steps 5 of the proof of Theorem 2.

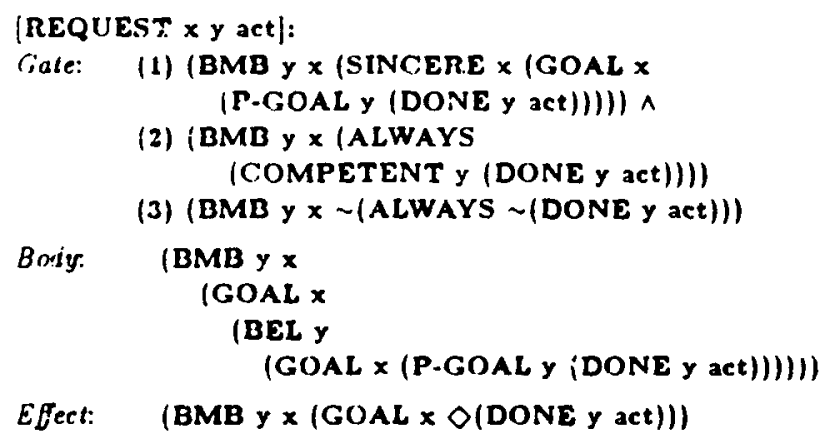

This summary allows us to conclude that any action preserving the Gate and making the Body true makes the Effect true.
Conditions (2) and (3) are theorems and hence are always preserved. Condition (1) was preserved by assumption.

Searle's conditions for requesting are captured by the above. Specifically, his "propositional content" condition, which states that one requests a future act, is present as the Efert because of Theorem 2. Searle's first "preparatory" condition -- that the hearer be able to do the requested act, and that the speaker think so is satisfied by condition (2). Searle's second preparatory condition - that it not be obvious that the hearer was going to do the act anyway - is captured by our conditions on persistence, which state when an agent can give up a persistent goal, that is not one of maintenance, when it has been satisfied.

Grice's "recognition of intent" condition $[12,13]$ is satisfied since the endpoint in the chain (step 9) is a goal. Hence, the speaker's goal is to get the hearer to do the act by means, in part, of the (mutual) recognition that the speaker's goal is to get the hearer to do it. Thus, according to Grice, the speaker has meant nn that the hearer should do the act. Searle's revised Gricean condition, that the hearer should "understand" the 'it. eral meaning of the utterance, and what illocutionary art the utterance "counts as" are also satisfied, provided the summary is mutually known. ie

\subsection{Nonserious Requests}

Two questions now arise. First, is this not overly complicated? The answer, perhaps surprisingly, is "No". By applying this REQUEST theorem, we can prove that the utterance of an im. perative in the cireumstances specified by the Gate results in the EGect, which is as simple a propositional attitude as anyone would propose for the effect of uttering an imperative - namely that it is mutually believed that the speaker's goal is that the bearee eventually do the act. The Body need never be considered

\footnotetext{
"The further elaboration of this point that it deserves is outside the scope - of this paper.
} 
unless one of the gating conditions fails.

Then, if the Body is rarely needed, when is the "extra" embedding (GOAL speaker (BEL hearer ...)) attitude of use? The answer is that these embeddings are essential to preventing nonserious or insincere imperatives from being interpreted unconditionally as requests. In demonstrating this, we will show how Searle's "Sincerity" condition is captured by our SINCERE predicate.

The formula (SINCERE speaker p) is false when the speaker does something to get the hearer to believe he, the speaker, has the goal of the hearer's believing $p$, when he in fact does not have the goal of the hearer's knowing that p Let us see see how this would he applied for "lio jump in the lake". uttered idiomatically. Notice that it could be uttered and meant as a request, and we should be able tu capture the distinction between serious and nonserious uses. In the case of uttering this imperative, the content of SINCERE. P $p=($ (:OAL speaker (P-GOAL hearer (DONE hearer [JUMP-INTO Lake (]))).

Assume that it is mutually known/believed that the lake is frigidly cold (any other conditions leading to $\sim$ (GOAL $\times$ p) would do as well. e.g., that the hearer is wearing his best suit, or that there is no lake around). So, by a reasonable axiom of goal formation. no one has goals to achieve states of affairs that are ohjertionable (assume what is "ohjectionable" involves a weighing of alternatives). So, it is mutually known/believed that -(GOAL speaker (DONE hearer [JUMP-INTO Lakel)), and so the speaker does not believe he has such a goal. 17 The consequent to the implication defining SINCERE is false, and because the result of the imperative is a mutual belief that the speaker's goal is that the hearer think he has the goal of the hearer's jumping into the lake. the antecedent of the implication is true. Hence, the speaker is insincere or not serious, and a request interpretation is blorked. is

In the case of there not being a lake around, the speaker's goal cannot be that the hearer form the persistent goal of jumping in some non-existent lake. since by the Vo Futslity property, the hearer will not adopt a goal if it is unachievable, and hence the speaker will not form his goal to achieve the unachievable state of affairs (that the hearer adopt a goal he cannot achieve). Hence. since all this is mutially believed, using the same argument, the speaker must be insincere.

\section{Nonspecific requests}

The ability conditions for requests are particularly simple, since as long as the hearer knows what action the speaker is referring to. he can always do it. He cannot, however, always bring about some goal world. An important variation of requesting is one in which the speaker does not specify the act to be performed; he meroly expresses his goal that some p be made true. This will be captured by the action [IMPER y "p] for "make $p$ true". Here,

\footnotetext{
"The speaker's expressed goal is that the hearef form a persintent goul to jump in the lake. But, by the Inevitable Conoequences lemms, given that a c.o.e. satisfying the speaker's goal also has the hearer's eventually jumping in (since the hearer knows what to do), the speaker's goad is also a c.o.e. in which the hearer eventually jumps in. In the same way, the speaker's goal would also be that the hearer eventually gets wet.

"However, we do not say what else might be derivable. The apenker's true goals may have more to do with the manner of his action (e.g., tone of voicel, than with the content. All we have done is demonstrate formally how a hearer could determine the utterance is not to be taken at face value.
}

in planning this act, the speaker need only believe the hearer thinks it is mutually believed that it is always the case that the hearer will eventually find a plan to bring about $p$. Although we cannot present the proof that performing an [IMPER $x$ y $p$ ] will make $O_{p}$ true, the following is the illocutionary summary of that proof: [NONSPECIFIC-REQUEST $x$ y $p$ ]:

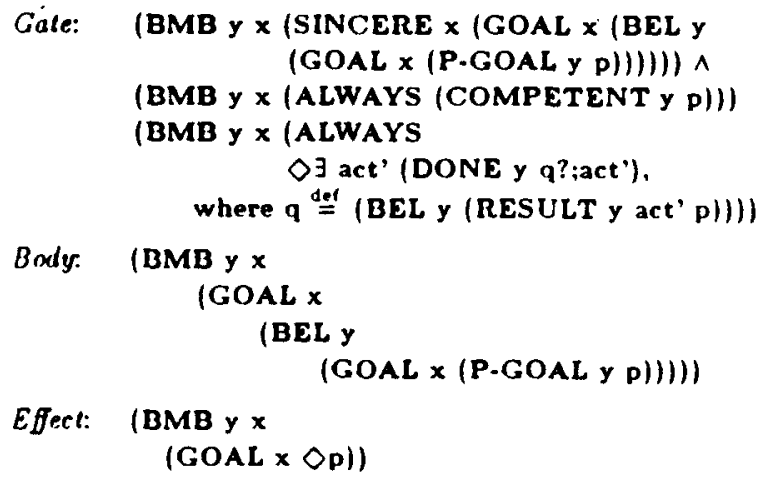

Since the speaker only asks the hearer to make $p$ true. the ability conditions are that the hearer think it is mutually believed that it is always true that eventually there will be some act such that the hearer believes of it that it achieves $p$ for he will believe it is impossible for him to achieve). The speaker need not know what act the hearer might choose.

\section{On summarization}

Just as mathematicians have the leeway to decide which proofs are useful enough to be named as lemmas or theorems, so too does the language user. linguist. computer system, and speech act theoretician have great leeway in deciding which summaries to name and form. Grounds for making such decisions range from the existence of illocutionary verbs in a particular language, to efficiency. However. summaries are flexible - they allow for different languages and different agents to carve up the same plans differently. 12 Furthermore, a summary formed for efficiency may not correspond to a verb in the language.

Pbilosophical considerations may enter into how much of a plan to summarize for an illocutionary verh. For example, most illocutionary acts are considered successful when the speaker has communicated his intentions, not when the intended effect has taken hold. This argues for labelling as Effects of summaries intended to capture illocutionary acts only formulas that are of the form (BMB hearer speaker (GOAL speaker p)), rather than those of the form (BMB hearer speaker $p$ ) or (BEL hearer $p$ ), where $p$ is not a GOAL-dominated formula. Finally, summaries may be formed as conversations progress.

The same ability to capture varying amounts of a chain of inference will allow us to deal with multi-utterance or multiagent acts, such as, betting, complying, answering, etc., in which there either aceds to be more than one act (a successful bet roquires an offer and an acceptance), or one act is defined to require the presence of another (complying makes sense only in the presence of a previous directive). For example, where REQUEST captured the chain of inference from step 2 to step 5 , one called COMPLY could start at 5 and stop at step 9.

\footnotetext{
${ }^{10}$ Remember, summaries are actually betiefs of agents, and those beliefs need not be shared.
} 
Thus, the notion of characterizing illocutionary acts as lemmalike summaries, i.e., as chains of inference subject to certain conditions, buys us the ability to encapsulate distant inferences at "one-shot".

\subsection{Ramifications for Computational Models of Language Use}

The use of these summaries provides a way to prove that various short-cuts that a system might take in deriving a speaker's goals are correct. Furthermore, the ability to index summaries by their Bodies or from the utterance types that could lead to their application (e.g., for utterances of the form "(Yan you do $\langle X>$ ") allows for fast retricval of a lemma that is likely to result in goal recognition. By an appropriate organization of summaries $|5|$, a system can attempt to apply the most comprehensive summaries first, and if inapplicable. can fall back on less comprehensive ones, eventually relying on first principles of reasoning about actions. Thus, the apparent dificulty of reasoning about speaker-intent can be tamed for the "short-circuited" cases, but more general-purpose reasoning can deployed when necessary. llowever, the complexities of reasoning abont others' betiels and goals remains.

\section{Extensions: Indirection}

Indirection will be modeled in this framework as the derivation of propositions dealing with the speaker's goals that are not stated as such by the initial propositional attitude. For example, if we can conclucte (rom (BMB y $\times$ (GOAL $\times$ (GOAL y p)) that (BMB y $\times$ (GOAL $\times$ (GOAL y $\diamond q)$ )), where $p$ does not entail q, then. "loosety", we will say an indirect request has heen made by $x$.

(iiven the properties of $\bigcirc$. (GOAL $\times$ p) $\supset($ (GOAL $\times O P)$ is a theorem. (GOAL $x$ ) and (GOAL $x \sim p$ ) are mutually unsatisfiable, hitt (COAL $\times$ ON) and (COOAL $\times$ O p) are jointly sialls fialle. For example, (GOAL BILL OHAVE BILL HAMMERI)I) and (GOAL BILL O(HAVE JOHN HAMMER1)) roukl both be part of a description of Bill's plan for John to get a hammer and give it to him. Such a plan could be triggered by Bill's merely saying "Ciet the hammer" in the right circumstances, such as when Bill is on a ladder plainily hoiding a nail. 30 A subsequent paper will demonstrate the conditions under which such reasoning is sound.

\section{Concluding Remarks}

This paper has demonstrated that all illocutionary acts need not be primitive. At least some can be derived from more basic principles of rational action, and an accounc of the propositional attitudes affected by the uttering of sentenees with dectarative. interrogative. and imperative moods. This account satisfies a number of eriteria for a good theory of illocutionary acts.

- Most elements of the theory are independently motivated. The iheory of rational action is motivated independently from any notions of communication. Similarly, the properties of cooperative agents are also independent of communication.

\footnotetext{
${ }^{20}$ Notice that mott theories of speech acte would treat the above utterance 2 on'y a direet request. We do not.
}

- The characterization of the result of uttering sentences with certain syntactic moods is justified by the results we derive for illocutionary acts, as well as the results we cannot derive (e.g., we cannot derive a request under conditions of insincerity).

- Summaries need not correspond to illocutionary verhs in a language. Different languages could capture different parts of the same chain of reasoning, and an agent might have formed a summary for purposes of efficiency, but that summary need not correspond to any other agent's summary.

- The rules of combination of illocutionary acts (characterizing, for example, how multiple assertions could constitute the performance of a request) are now reduced to miles for combining propositional contents and attitudes. Thus, multi-utterance illocutionary acts can be handled by accumulating the speaker's goals expressed in multiple utterances, to allow an illocutionary theorem to be applied.

- Multi-art utterances are also a natural outgrowth of this approach. There is no reason why one cannot apply inuliple illocutionary summaries to the result of uttering a sentence. Those summaries, however, need not correspond in illoru. tionary vertss.

- The theory is naturally extensible to indircetion (to be argued for in another paper), to other illocutionary act, such as questions, rommands, informs, assertions, and to the act of referring $[8]$

Finally. although illorutionary act recosmition may be strictly unneressary, given the complexity of nur proofs, it is likely to be useful. Fissentially. such recognition would amouns to the application of illorutionary summaries theorems to discover the speakeris goal(s).

\section{Acknowledgements}

We would like to thank Tom Blenko, lierb (:lark, Michael Georgulf, David lorael, Brb Moore, Cient Nunterg. Furnando Pereira, Ray Perrault, Stan Rosenschein, Ivan sag, and Moshe Vardi for valuable disrussions.

\section{References}

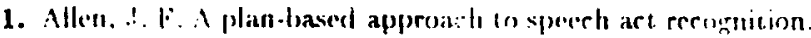
Tertonical lerport ial. Departmeat of romputer sicience. Iniversity of Tumuto, Jamuary. 1979.

2. Allen. A. F.. Frisch. A. M.. of Litman. D. A. AR(;O)T: The Rochester dialogise system. Proceetlings of the lialuonul Conference on Artificial Intelligenre, Pittshureh. Pinusylvania, 1082, 6ro, -70

3. Appett, D. Planning Natural Languaye Vitterunces to Sistisfy Multiple Gools. Ph.D. Th.. Stanford University, Stanford, California, December 1981.

4. Austin, J. L. How to do things with words. Oxford University Press, London, 1962. 
5. Brachman. R., Bobrow, R., Cohen, P., Klovstad, J., Webber, B. L., \& Woods, W. A. Researeh in natural language understanding. Technical Report 4274, Bolt Beranek and New man lne., August, 1979.

6. Bruce, B. C., \& Newman, D. Interacting plans. Cognitive Science 2, 3, 1978, pp. 195-233.

7. Clark, H. H., \& Marshall, C. Definite reference and mutual knowledge. In Elements of Discourse Understanding, Academic Press, Joshi, A. K., Sag. I. A., \& Webber, B., Eds., New York, 1081.

8. Cohen, P. R. The Pragmatirs of Referring and the Modality of Communication. Computational linguistics 10,2, 1984 . pp. $97-1.46$.

9. Cohen, P. R. On Knowing what to Say: Planning Speech tets. Ph.D. Th., University of Toronto. Toronto, January 1978. Terhnical Report No. 118. Dept. of Computer Sicience.

10. ('ohen, P. R.. \& Levesque, H. J. Sipeerh Acts and the Rerngnition of Shared Plans. Pror. of the Third Biennial Conference, (anadian Society for Computational studies of Intelligence, Vietnria. B. (., May, 1980, 26,3-271.

11. Bmerson, F.. A., and Halpern, J. Y. "Sometimes" and "Not Never" Revisited: On Branching versus linear Time. ACMA symposium on Principles of Promgrumming Langunges, 198:3.

12. (irice. II. P. Mraning. Philosophiml Review 66, 1957, pp. $377 \cdot 38 x$.

13. Grice. H. P'. Litteret's Meaning and Intentions. Philosnphical Review 63, 2, 1969, pp. 1/7-177.

14. Grice, H. P. Logic and conversation. In Cole., P. and Morgan, J. I., Eds., Syntaz and Semantics: Speech Acts, Academic Press. New York, 1975.

16. Halpern, J. Y., and Mosesy, Y. (). A Ciuide to the Modial Logies of knowledge and Belief. Pror. of the Viuth Inter. national Joint Conference on Artifirtul intelligence, l.J :Al, Los Angeles, ('alif., August, 108i).

Levesque, Hector. J. A logic of implicit and explicit belief. Proceedings of the National Conjerence of the Ameriran Ascintion for Artificial Intelligence, Austin, Texas, 1084.

esque, H. J., \& Cohen, P. R. A Simplified l.ogic of Inceraction. In preparation

18. MeCarthy. J.. \& Ilayes. P. J. Some Philosophical P'roblems from the sitandpoint of Artificial Intedligeruere. In Murhene incelligenes: American kilsevier. B. Meltzer \& D. Mirhie. Eds.. View liork. 1969.

19. McDermott, D. A temporal logic for reasoning about processes and plans. Cognitive Scrence 5, 2, 1982, pp. 101-155.

20. Moore, K. C. Reasoning about Knowledge and Action. Technical Note 191, Artificial Intelligence Center, SRI Intemational, October, 1980.

21. Morgan, J. L. Two types of convention in indireet speecb acts. In Syntax and Semantics, Volume 9: Pragmatics, Academic Press, P. Cole. Ed., New York, 1978, 261-280.
22. Perrault, C. R.. \& Allen, J. F. A Plan-Based Analysis of Indirect Speech Acts. American Journal of Computational Linguistics 6, 3, 1980, pp. 167-182.

23. Perrault, C. R., \& Cohen, P. R. It's for your own good: A note on inaccurate reference. In Elements of Discourse Underslanding, Cambridge University Press, Joshi, A., Sag, I., \&: Webber, B., Fds., Cambridgc, Mass., 1981.

24. Schifter, S. Mcaning. Oxford University Press, London. 1972.

25. Schmidt, D. F., Sridharan, N.S., \& Goorison, J. L. The plan recognition problem: An intersection of artificial intelligence and psychology. Artificial Intelligence 10, 1979, pp. 45-8.3.

26. Searle, J. R. Speech acts: In essay in the philnsophy of language. Cambridge liniversity Preas, lambridge, 1969.

27. Sidner, $(\therefore$ L., Bates, M., Bobrow. R. J., Brachman, R. J., Cohen, P. R.. Isracl. D. J., Welber, B. L.., \& Woods, W. A. Research in knowledge representation for natural language understanding. Annual Report 1785, Bolt. Beranek and Newman Inc., November, 1981.

28. Vanderviken. D. A Model-Theoretic Semanties for Illocutionary Forer. Logique et Anulyse $26,103-104,1983$, pp. 359-3105. 


\section{Appendix}

Proof of Theorem 1:

First, we need a lemma:

Lemma $3 \forall a(D O N E \times(\mid B E L \times($ AFTER a $p)) \wedge($ COMPETENT $\times p) \mid ? ; a) \supset p$

Proof:

\begin{tabular}{|c|c|c|}
\hline $\begin{array}{l}1 . \\
2 .\end{array}$ & $\begin{array}{l}\forall a(\text { DONE } \times \|(B E L \times(\text { AFTER a p }) \wedge(\text { COMPETENT } \times p) \mid ? ; a) \\
(B E L \times(\text { AFTER } \times \text { p })) \wedge(\text { COMPETENT } \times \text { p) } \supset(\text { AFTER a p) }\end{array}$ & $\begin{array}{l}\text { Ass } \\
\text { Def. of } \\
\text { COMPETENT, MP }\end{array}$ \\
\hline 3. & $\forall \mathrm{a}$ (DONE $\times($ AFTER a p)?;a) & $2, \mathrm{P}_{4}$ \\
\hline $\begin{array}{l}4 . \\
5 .\end{array}$ & $\stackrel{p}{\forall a}($ DONE $\times \|(B E L \times($ AFTER a p $) \wedge($ COMPETENT $\times p) \mid ? ; a) \supset p$ & $\begin{array}{l}\text { 3, P3 } \\
\text { Impl. Intr. }\end{array}$ \\
\hline
\end{tabular}

Theorem 1. $\forall y(P-G O A L$ y $p) \wedge($ ALWAYS (COMPETENT y p)) $\supset O(p \vee(B E L$ y (ALWAYS $\sim p))$

Proof:

\begin{tabular}{|c|c|c|}
\hline $\begin{array}{l}1 . \\
2 . \\
3 . \\
4 .\end{array}$ & $\begin{array}{l}\text { (P.GOAL y (DONE y act)) A (ALWAYS (COMPETENT y (DONE y act))) } \\
O(\exists a(D O N E \text { y }((B E L \text { y (AFTER a p)))?:a) } \vee(B E L \text { y (ALWAYS } \sim p)) \\
O(p \vee(B E L \text { y (ALWAYS } \sim p)) \\
(P-G O A L \text { y (DONE y act)) A (ALWAYS (COMPETENT y (DONE y act))) } \\
O(p \vee(B E L \text { y (ALWAYS } \sim p))\end{array}$ & $\begin{array}{l}\text { Ass. } \\
\text { 1. P25, MP } \\
\text { L3, P8, : } \\
\text { Impl. Intr., } 3\end{array}$ \\
\hline
\end{tabular}

